\title{
Correction: Physical Warmth and Perceptual Focus: A Replication of IJzerman and Semin (2009)
}

\author{
Janneke D. Schilder, Hans IJzerman, Jaap J. A. Denissen
}

There is an error in the first sentence of the fourth paragraph in the Procedure section of the Methods. The data are available from Open Science Framework instead of Dataverse. The correct sentence is: The questionnaire programmed in Qualtrics was offered in Dutch and took on average 15 minutes to complete (on a notebook (Acer) or an iPad; the exact questionnaire in Dutch are available via https://osf.io/ijxhr/).

\section{Reference}

1. Schilder JD, IJzerman H, Denissen JJA (2014) Physical Warmth and Perceptual Focus: A Replication of IJzerman and Semin (2009). PLoS ONE 9(11): e112772. doi: 10.1371/journal.pone.0112772 PMID: 25402343

\section{G OPEN ACCESS}

Citation: Schilder JD, IJzerman H, Denissen JJA (2015) Correction: Physical Warmth and Perceptual Focus: A Replication of IJzerman and Semin (2009). PLoS ONE 10(5): e0129636. doi:10.1371/journal. pone. 0129636

Published: May 28, 2015

Copyright: $\odot 2015$ Schilder et al. This is an open access article distributed under the terms of the Creative Commons Attribution License, which permits unrestricted use, distribution, and reproduction in any medium, provided the original author and source are credited. 